\title{
Геотриадное измерение территории
}

П.М. Мазуркин, С.И. Михайлова

Введение. Геотриадный подход подразумевает измерение территории тремя основными факторами иерархии «ландшафт + население + хозяйство».

После изучения особенностей распределения людьми земельных участков на данной территории следует исчислять население людей, животных и растений. А затем можно будет переходить к измерению параметров хозяйств (не только люди способны вести хозяйства, но и многие виды животных и даже растений, например, биогруппы деревьев).

Геотрион и геотриада. Великий химик Д.И. Менделеев системно представлял лесное дело как органичную территориальную часть сельского хозяйства. Вот что он отмечает в книге [1, с.300]: «Под сельским хозяйством обыкновенно понимают не одну специальную отрасль промышленного разведения животных и растений, но и всю деятельность, исходящую из владения поверхностью земли, например, лесное дело, охоту, рыбную ловлю, грунтовую перевозку и тому подобные первичные неизбежные формы промышленности, которыми живет еще не меньше $70 \%$... народа». По состоянию к 1906 г. на территории России проживало около 100 млн. людей.

В этой мысли Д.И. Менделеева присутствуют два общесистемных признака: во-первых, деревья как один из классов растений воспроизводятся сельскими жителями; во-вторых, любая поделочная работа из древесины срубленного дерева относится к первичной промышленности и также вполне может выполняться сельскими (и лесными) жителями.

В публикациях по рационализации природопользования появился термин «геотрион», объединяющий три различных объекта: население (людское), хозяйство и территорию. Поэтому можно записать структурную формулу: геотрион $=$ население человеческое + хозяйство людского населения + территория, занятая этим людским населением. 
При всей привлекательности эта формула имеет существенный недостаток в том, что она отражает антропоцентристский подход к изучению природных объектов. Но человек сам является частью природы, он является только одним из биологических видов, относящихся к царству животных.

Попытки выработки определений различным комплексным объектам были и ранее. Например, территориально-промышленный комплекс (Братский территориально-промышленный комплекс (ТПК), Усть-Илимский комплекс и др.) является структурой, содержащей всего два объекта по укороченной формуле ТПК = хозяйство + территория.

Системный подход позволил разрозненные объекты «людское население», «хозяйство» и географическое понятие «территория» рассматривать совместно. И во второй половине $\mathrm{XX}$ века в этом был практический смысл. Но скоро оказалось, что частное рассмотрение только одного хозяйства (леспромхоз), хозяйства с территорией (колхоз, совхоз, лесхоз, а в дальнейшем попытки создания так называемых комплексных лесных или сельскохозяйственных предприятий с верховенством доктрины покорения природы человеком) было заведомо обречено на провал.

Из трех объектов «ландшафт», «население» и «хозяйство» образуется одно по иерархическому смыслу сочетание, названное нами геотриадой, то есть в этом случае получаем структурную формулу вида

$$
\text { геотриада }=\text { ландшафт }+ \text { население }+ \text { хозяйство. }
$$

При этом термин «хозяйство» понимается расширительно, так как многие животные, птицы, насекомые и растения имеют хозяйства.

Например, чем старее дерево, тем больше разнообразие его хозяйства внутри пространства места произрастания. На дереве имеются дупла белки, совы и диких пчел, места обитаний колоний насекомых и микроорганизмов.

Территориальный принцип. Основной метод решения природнохозяйственных задач - это территориальный, еще точнее - бассейновый, подход к оценке природных объектов, а в последующем выделение из них тех свойств в виде потоков вещества, энергии и информации, которые 
называются человеком как природные ресурсы. Такой подход применим и к горным ландшафтам и к объектам рекультивации нарушенных земель.

Предлагаемые нами способы, например [3], измерения территории относятся к инженерной биологии (экологии) ландшафтов и административных территориальных образований.

\section{Существующий способ оценки экологического состояния}

территории. Известен способ измерения состояния территории [2, с.362-363, рис. 117], включающий поддержание экологического равновесия на данной территории специально выделенными участками ранее существовавший или желаемый баланс между преобразованными человеком экосистемами и естественными экосистемами в процентах от общей площади.

При различных соотношениях значений площади земельных участков под преобразованными и естественными экосистемами изменяется суммарный эколого-социально-экономический эффект (сумма полезностей). При этом целесообразное экологическое равновесие (100\% полезностей) возникает при соотношении 40 \% первых и 60 \% вторых.

Недостатком является то, что этот способ был создан под влиянием антропоцентризма, на это указывает то, что на первое место ставятся преобразованные людьми экосистемы, а на второе - естественные экосистемы. Это приводит к тому, что часто антропогенные нагрузки по площади преобразованных экосистем доводятся до $100 \%$ и только затем люди начинают задумываться над уже свершившимися экологическими катастрофами. При этом отсутствует количественное измерение относительного эффекта и изменения площади экосистемы.

Технический результат предлагаемого способа - повышение точности измерения экологического состояния территории за счет применения природного и естественного объекта - фитоценоза. Общеизвестно, что границы экосистемы определяются фитоценозом. Однако сам фитоценоз может иметь, из-за расстройства структуры и свойств человеческой деятельностью, нечеткие территориальные контуры и земельные участки. 
Поэтому предлагается применить в качестве измерителя растительный покров, что позволяет применять существующую классификацию земельного кадастра по категориям земельных участков. Терминологически важно иметь в виду, что прототип нечетко определяет состав понятия «естественные экосистемы», включая туда (см. там же, с.443-444) любые не тронутые или слабо измененные человеком природные объекты: «Существует и такое мнение, что в агроландшафтах леса, луга, водные пространства должны занимать не менее 30 \% общей площади».

Ошибкой здесь является отнесение водных объектов к неизмененной части экосистемы. Эта ошибка исключается при принятии в качестве объекта измерения растительного покрова. Причем в растительный покров нами не включаются участки земель под многолетними травами, так как они подвержены пахоте и включены в систему севооборотов.

\section{Предлагаемый способ оценки экологического состояния.}

Указанный технический результат достигается тем, что способ измерения состояния территории по площади растительного покрова, включающий поддержание экологического равновесия на данной территории специально выделенными участками земель ранее существовавший или желаемый баланс между преобразованными человеком экосистемами и естественными экосистемами, измеряемыми в процентах от общей площади, причем при различных соотношениях значений площади земельных участков под преобразованными и естественными экосистемами изменяется суммарный экологический, социальный и экономический эффект, а целесообразное экологическое равновесие достигается при 100 \% полезного эффекта, который возникает при соотношении 40 \% первых и $60 \%$ вторых, отличающийся тем, что измеряется общая площадь территории и площадь растительного покрова на этой территории, затем вычисляется активность растительного покрова как отношение его площади к общей площади данной территории, при этом статистическим моделированием выявляется закономерность изменения общего эффекта в зависимости от активности 
растительного покрова, после этого по вычисленному значению активности растительного покрова количественно оценивается состояние территории как существующий баланс между естественными экосистемами, содержащими растительный покров, и остальной частью общей площади территории, сравнением расчетного по существующей активности растительного покрова эффекта с желаемым при полном 100-процентном эффекте определяется относительный экологический ущерб от несбалансированности территории по растительному покрову, а после этого для достижения желаемого баланса между территорией и её растительным покровом принимаются экологоэкономические мероприятия для повышения активности проектируемого растительного покрова.

Общая площадь территории учитывается совместно площади суши с водными объектами, а при превышении площади водных объектов 5процентной доли от территории экосистемы с растительным покровом за значение общей площади принимается площадь суши, без учета акватории водных объектов.

После составления табличной модели статистическим моделированием выявляется среднестатистическая закономерность изменения относительного общего экологического, социального и экономического эффекта в зависимости от активности растительного покрова по формуле

$$
E=E_{0}+a_{1} \mu^{a_{2}} \exp \left(-a_{3} \mu^{a_{4}}\right)
$$

где - относительный суммарный экологический, социальный и экономический эффект (относительная сумма полезностей);

$E_{0}$ - начальный относительный суммарный эффект на данной территории при полном отсутствии на ней растительного покрова;

$\mu$ - активность растительного покрова на данной территории, вычисляемая как отношение его площади к общей площади территории;

$a_{1} \ldots a_{4}$ - параметры закономерности, значения которых зависят от природных свойств экосистемы с растительным покровом; 
$a_{1} \mu^{a_{2}} \exp \left(-a_{3} \mu^{a_{4}}\right)$ - биотехнический закон проф. П.М. Мазуркина [4 - 9], для данной территории показывающий структурную динамику влияния растительного покрова на относительный суммарный эффект, причем по прототипу (по графику Н.Ф. Реймерса в зеркальном изображении) среднестатистическая закономерность изменения общего эффекта в зависимости от активности растительного покрова изменяется по формуле

$$
E=0,25110+1,01425 \mu^{0,41950} \exp \left(-0,71669 \mu^{3,80376}\right) .
$$

Относительный экологический ущерб $\Delta E$ от недостатка растительного покрова на данной территории вычисляется как выражение

$$
\Delta E=1-E_{0}-a_{1} \mu^{a_{2}} \exp \left(-a_{3} \mu^{a_{4}}\right) .
$$

Сущность технического решения заключается в том, что за основу способа принимается биоцентристский подход к оценке деятельности человека, поэтому главным объектом измерения становится растительный покров, который характеризует фитоценоз, а границами фитоценоза в полной мере географически определяется сама экосистема.

Положительный эффект достигается тем, что данные земельного кадастра позволяют вычислять площадь растительного покрова к общей площади территории данной экосистемы или же административного района.

Поэтому предлагаемый способ легко адаптируется в существующие программные комплексы для расчетов по земельным кадастрам.

Методика реализации предлагаемого способа. Пусть дана некая территория экосистемы или административного образования. В ней всегда присутствует растительный покров, так как в ином случае люди на такой территории постоянно не живут. Вначале измеряется (или задана земельным кадастром, ежегодно уточняемым службами учета недвижимости) общая площадь территории и площадь растительного покрова на этой территории. Затем вычисляется активность растительного покрова как отношение его площади к общей площади территории. 
Далее моделированием выявляется закономерность изменения общего относительного эффекта от активности растительного покрова. После этого количественно оценивается состояние территории как существующий баланс между растительным покровом и остальной частью территории экосистемы или административного образования. Затем сравнением расчетного по активности растительного покрова эффекта с желаемым при полном 100процентном эффекте определяется относительный экологический ущерб от несбалансированности территории по растительному покрову.

Для достижения желаемого баланса между территорией и её растительным покровом определяются эколого-экономические и социальные мероприятия, повышающие активность растительного покрова. После этого приступают к разработке проектов природообустройства конкретных ландшафтов и рационализации природопользования в них.

Уравнение (2) для средней полосы России содержит две составляющие, поэтому можно её записать как сумму отдельных составляющих в виде

$$
E=E_{1}+E_{2} .
$$

На рис. 1 приведен график формулы (2).

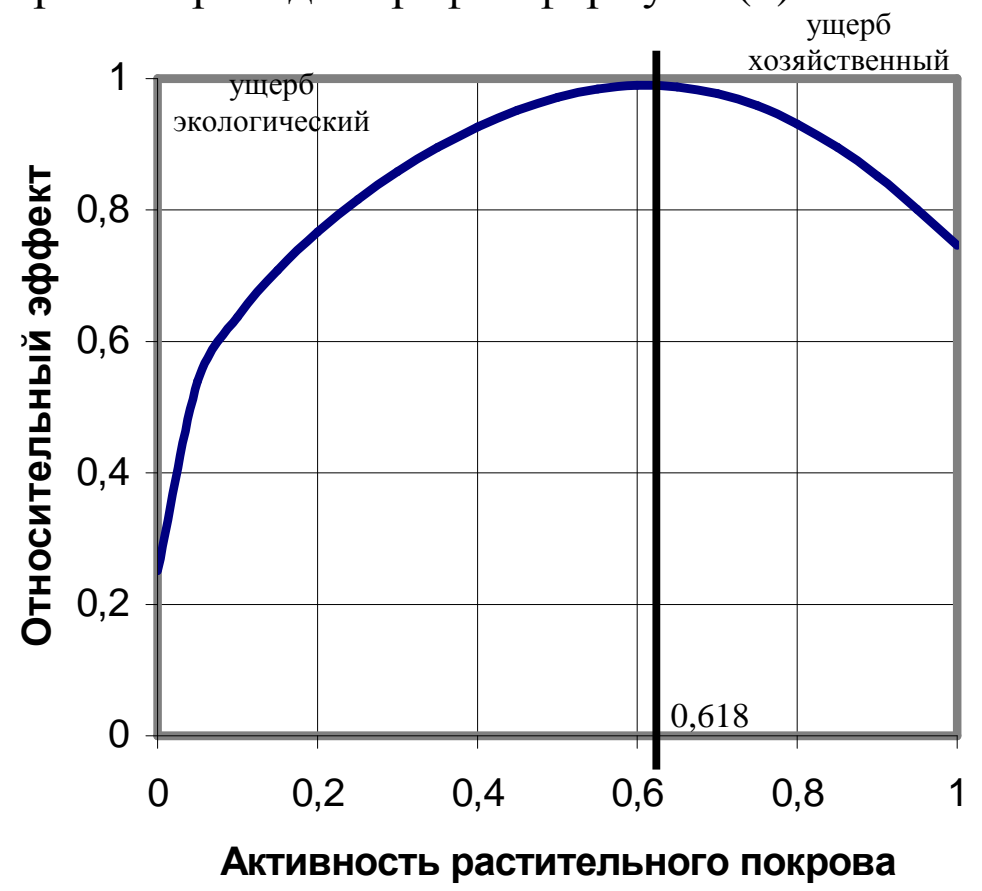

Рис. 1. График изменения относительного эффекта от активности растительного покрова 
Первая составляющая является постоянным членом и он показывает суммарный эффект при полном отсутствии растительного покрова. Вторая составляющая является биотехническим законом в общей форме, который был предложен проф. П.М. Мазуркиным для описания биотехнического поведения живого (по В.И. Вернадскому) вещества.

Максимальная относительная погрешность формулы (2) к графику Н.Ф. Реймерса составляет всего 2,27 \% (табл. 1). Тогда доверительная вероятность формулы (2) будет не ниже $100-2,27=97,73 \%$. Высокое доверие позволяет отказаться от графика, не применять в проектной деятельности табличную модель и пользоваться в расчетах формулой (2).

На схеме рис. 1 указаны зоны относительного экологического ущерба и хозяйственного ущерба. График по Н.Ф. Реймерсу является усреднением, который можно применять к средней зоне Европейской части России.

Таблица 1

Изменение относительного суммарного эффекта

\begin{tabular}{|c|c|c|c|c|c|c|c|}
\hline \multirow{2}{*}{$\begin{array}{c}\text { Процент } \\
\text { преобразов } \\
\text { анных } \\
\text { экосистем }\end{array}$} & \multirow{2}{*}{$\begin{array}{c}\text { Активность } \\
\text { растительн } \\
\text { ого покрова } \\
\mu\end{array}$} & \multirow{2}{*}{$\begin{array}{c}\text { Общий } \\
\text { эффект по } \\
\text { факту } \hat{E}\end{array}$} & \multicolumn{3}{|c|}{ Расчетные значения по модели (2) } & \multicolumn{2}{|c|}{ Составляющие } \\
\hline & & & $\begin{array}{c}\text { Расчетны } \\
\text { й эффект } \\
E\end{array}$ & $\begin{array}{l}\text { Остаток } \\
\varepsilon=\hat{E}-E\end{array}$ & \begin{tabular}{|c|} 
Относит. \\
погрешность, \\
$\% \Delta=100 \varepsilon / \hat{E}$
\end{tabular} & $E_{1}$ & $E_{2}$ \\
\hline 0.0 & 1.000 & 0.750 & 0.746 & 0.004 & 0.53 & 0.251 & 0.495 \\
\hline 0.2 & 0.800 & 0.920 & 0.931 & -0.011 & -1.20 & & 0.680 \\
\hline 0.4 & 0.600 & 1.000 & 0.990 & 0.010 & 1.00 & & 0.739 \\
\hline 0.5 & 0.500 & 0.980 & 0.971 & 0.009 & 0.92 & & 0.720 \\
\hline 0.6 & 0.400 & 0.920 & 0.927 & -0.007 & -0.76 & & 0.676 \\
\hline 0.8 & 0.200 & 0.750 & 0.767 & -0.017 & $-\underline{2.27}$ & & 0.516 \\
\hline 0.9 & 0.100 & 0.650 & 0.637 & 0.013 & $\overline{2.00}$ & & 0.386 \\
\hline 1.0 & 0.000 & 0.250 & 0.251 & -0.001 & -0.40 & & 0.000 \\
\hline
\end{tabular}

Примечание: Максимальное значение относительной погрешности подчеркнуто.

На рис. 2 приведен пример активности растительного покрова.

Для других климатических и почвенно-грунтовых зон Российской Федерации необходимо формировать табличные данные для уточнения значений параметров модели (2) или же применять рекомендации проф. Н.Ф. Реймерса по карте России [2, с.430].

Для реализации сдвига по двойной стрелке на рис. 2 потребуются мероприятия, чтобы обеспечить сдвиг от реальной активности растительного покрова до рационального уровня 0,618 , то есть до золотой пропорции. 
При этом экологический ущерб будет уменьшаться.

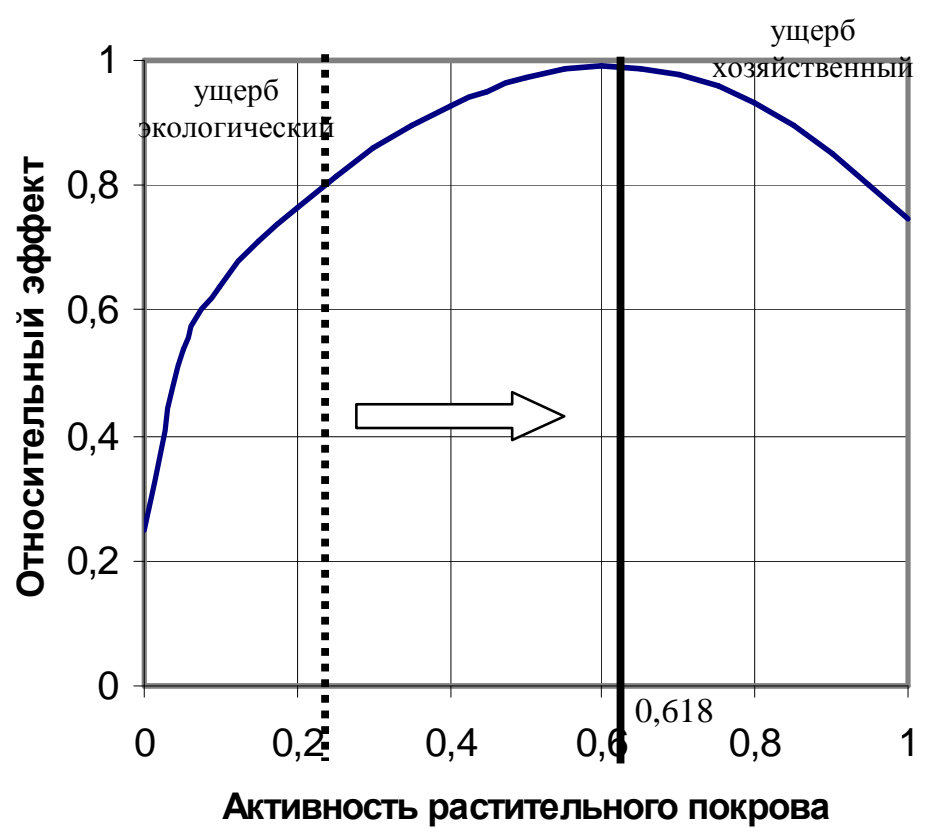

Рис. 2. Пример относительного эффекта от малой активности растительного покрова (стрелкой показана необходимость повышения активности до золотой пропорции)

Из всего растительного покрова выделяется по интенсивности биологического продуцирования травяной покров, который в средней зоне Европейской части России имеет высокую ежегодную продуктивность даже по сравнению с лесными земельными участками. Наиболее пригодны для геотриадных измерений естественные луга.

Распределение, например, административных районов Республики Марий Эл (РМЭ), выполняется по рангам $r=0,1,2, \ldots$, причем ранжирование выполнено по убыванию урожайности сена с естественных сенокосов.

Затем этот ранг становится объясняющей переменной.

К сожалению, из статистических сборников разных лет по РМЭ удалось найти достоверную статистическую выборку только за 1975 год.

Все 14 районов РМЭ распределяются (рис. 3) по урожайности сена (табл. 2) с естественных сенокосов в виде формулы

$$
\begin{gathered}
q=15.0394 \exp \left(-0,21802 r^{0,69670}\right)- \\
-6,2071 \cdot 10^{-9} r^{8,24823} \cos (\pi r / 5,28450+4,06118),
\end{gathered}
$$

где $q$ - урожайность сена с естественных сенокосов, џ/га, 
$r$ - ранг при ряде (предпорядке предпочтения) $r=0,1,2,3, \ldots$, причем ранги присваиваются по убыванию урожайности сена.

Первая составляющая уравнения (5) является естественной закономерностью в виде устойчивого экспоненциального закона гибели. Вторая составляющая показывает ранговое возмущение административных образований, то есть условной популяции преобразованных человеком

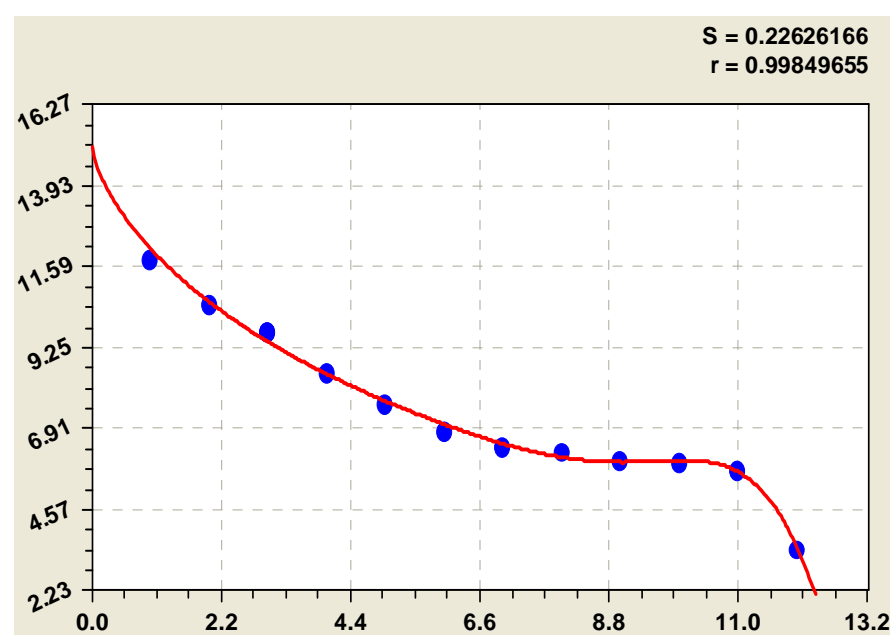
природных объектов, поэтому эта часть модели характеризует антропогенное воздействие на естественные сенокосы через изменение показателя урожайности травяного покрова.

Рис. 3. Ранговое распределение урожайности сена с естественных сенокосов РМЭ

Таблица 2

Фактические и расчетные значения урожайности сена. ц/га

\begin{tabular}{|c|c|c|c|c|c|c|c|c|}
\hline \multirow{2}{*}{$\begin{array}{c}\text { Сельский } \\
\text { район РМЭ }\end{array}$} & \multirow{2}{*}{$\begin{array}{c}\text { Ранг } \\
r\end{array}$} & \multirow{2}{*}{$\begin{array}{c}\text { Факт } \\
\hat{q}\end{array}$} & \multicolumn{3}{|c|}{ Расчетные значения (5) } & \multicolumn{2}{|c|}{ Составляющие } & \multirow{2}{*}{$\begin{array}{c}\text { Неустойч. } \\
K_{U}\end{array}$} \\
\hline & & & $q$ & $\varepsilon$ & $\Delta, \%$ & $q_{1}$ & $q_{2}$ & \\
\hline Волжский & 11 & 5,7 & 5,65 & 0,052 & 0,90 & 4,720 & $-0,928$ & $-0,197$ \\
\hline Горномарийский & 7 & 6,4 & 6,48 & $-0,076$ & $-1,19$ & 6,455 & $-0,021$ & $-0,003$ \\
\hline Звениговский & 10 & 5,9 & 6,00 & $-0,104$ & $-1,75$ & 5,085 & $-0,919$ & $-0,181$ \\
\hline Килемарский & 0 & 15,1 & 15,04 & 0,061 & 0,40 & 15,039 & 0,000 & 0,000 \\
\hline Куженерский & 8 & 6,1 & 6,09 & 0,013 & 0,21 & 5,944 & $-0,143$ & $-0,024$ \\
\hline Мари-Турекский & 9 & 6 & 5,95 & 0,049 & 0,81 & 5,490 & $-0,461$ & $-0,084$ \\
\hline Медведевский & 1 & 11,8 & 12,09 & $-0,293$ & $-2,49$ & 12,093 & 0,000 & 0,000 \\
\hline Моркинский & 12 & 3,4 & 3,41 & $-0,010$ & $-0,30$ & 4,390 & 0,980 & 0,223 \\
\hline Новоторъяльский & 6 & 6,8 & 7,03 & $-0,232$ & $-\underline{3,41}$ & 7,036 & 0,004 & 0,001 \\
\hline Оршанский & 2 & 10,5 & 10,56 & $-0,062$ & $-0,60$ & 10,562 & 0,000 & 0,000 \\
\hline Параньгинский & 3 & 9,7 & 9,41 & 0,288 & 2,97 & 9,412 & 0,000 & 0,000 \\
\hline Сернурский & 4 & 8,5 & 8,48 & 0,019 & 0,22 & 8,482 & 0,001 & 0,000 \\
\hline Советский & 3 & 9,7 & 9,41 & 0,288 & 2,97 & 9,412 & 0,000 & 0,000 \\
\hline Юринский & 5 & 7,6 & 7,70 & $-0,100$ & $-1,32$ & 7,703 & 0,003 & 0,000 \\
\hline
\end{tabular}

По амплитуде это волновое возмущение для травяного покрова является кризисным (отрицательный знак перед второй составляющей). Физически колебание показывает нестабильность поведения естественных сенокосов в различных сельских районах. 
В табл. 2 и далее приняты следующие условные обозначения:

$\hat{q}$ - фактические значения урожайности сена, ц/га;

$q$ - расчетные по готовой статистической модели (5) значения средней урожайности сена со всех сенокосов сельских районов РМЭ;

$\mathcal{E}$ - остатки, то есть абсолютная погрешность, как разница между фактическими и расчетными значениями изучаемого показателя, вычисляемые по формуле $\varepsilon=\hat{q}-q$;

$\Delta$ - относительная погрешность, вычисляемая из математического соотношения $\Delta=100 \varepsilon / \hat{q}, \%$.

Критерий неустойчивости $K_{U}$ травяного покрова оценивается коэффициентом приспособляемости травы к антропогенным нагрузкам и будет равна отношению второй составляющей формулы (5) к первой. Причем неустойчивость травы естественных сенокосов по сельским районам была в 1975 г. кризисной, а не адаптационной.

Результаты расчетов по составляющим формулы (5) и её адекватности статистической выборке приведены в данных табл. 2. По этим данным максимальная относительная погрешность статистической модели равна по абсолютной величине 3,41 \%, а доверие к формуле (5) не будет ниже 96,59\%.

Максимально кризисно неустойчивым является Моркинский сельский район. У него коэффициент приспособляемости, то есть коэффициент неустойчивости внутри популяции районов равен 0,223. Этот кризис в 1975 году произошел от неизвестной нам причины так, что при расчетном значении урожайности сена 4,39 ц/га произошло снижение на 0,98 ц/га и получилось по модели (5) урожайность сена с естественных сенокосов Моркинского района всего 3,41 ц/га. При этом относительная погрешность теоретического результата равна всего $0,30 \%$.

В структуре 14 сельских районов РМЭ адаптивно неустойчивыми в 1975 году были Волжский, Звениговский, Мари-Турекский и немного Кужененсркий сельские районы. Остальные районы были нейтральными. 


\section{Литература}

1. Менделеев, Д.И. Границ познанию познать невозможно / Составление, вступительная статья и комментарии Ю.И. Соловьева. -М.: Сов. Россия, 1991. - 592 с.

2. Реймерс, Н.Ф. Природопользование: Словарь-справочник / Н.Ф. Реймерс. - М.: Мысль, 1990. $-637 \mathrm{c}$.

3. Пат. 2293290 Российская Федерация, МПК G 01 С 13/00 (2006.01). Способ измерения площади водосбора реки по длине и падению притоков / Мазуркин П.М., Иванов А.А., Михайлова С.И., Волкова Л.О. (РФ); заявитель и патентообладатель Марийск. гос. тех. ун-т. - №2005101055/28; заявл. 18.01.2005; опубл. 10.02.2007, Бюл. № 4.

4. Мазуркин, П.М. Геоэкология: Закономерности современного естествознания: Научное изд. / П.М. Мазуркин. - Йошкар-Ола: МарГТУ, 2006. - 336 с.

5. Мазуркин, П.М. Закономерности устойчивого развития / П.М. Мпзуркин. Научное издание. - Йошкар-Ола: МарГТУ, 2002. - 302с.

6. Мазуркин, П.М. Лесистость и распаханность территории / П.М. Мазуркин, С.И. Васильева // Экология: Образование, наука, промышленность и здоровье: материалы II Международной научно-практической конференции. - Вестник БГТУ. - 2004. - №8.. Часть V. - C.83-85.

7. Мазуркин, П.М. Распределение площади эродированных земель / П.М. Мазуркин, С.И. Васильева // Экология - образование, наука и промышленность: сборник докладов международной научно-методической конференции. - Часть 2. - Белгород: БелГТАСМ, 2002. - С.241-246.

8. Мазуркин, П.М. Рациональное природопользование: учебное пособие. В 3-х ч. Ч. 1: Экологически ответственное землепользование / П.М. Мазуркин, С.Е. Анисимов, С.И. Михайлова; под ред. П.М. Мазуркина. - Йошкар-Ола: МарГТУ, 2006. - 176 с.

9. Мазуркин, П.М. Математическое моделирование. Идентификация однофакторных статистических закономерностей: Учебное пособие / П.М. Мазуркин, А.С. Филонов. Йошкар-Ола: МарГТУ, 2006. - 292 с. 